\title{
Evaluation of Surgical Antimicrobial Prophylaxis and Incidence of Surgical Site Infection at Borumeda Hospital, Northeast Ethiopia: Retrospective Cross-Sectional Study
}

This article was published in the following Dove Press journal:

Drug, Healthcare and Patient Safety

\section{Getachew Moges (iD) \\ Lielet Belete \\ Yohannes Mengesha (D) \\ Solomon Ahmed (D)}

Department of Pharmacy, College of Medicine and Health Sciences, Wollo University, Dessie, Ethiopia
Correspondence: Getachew Moges Email getachewmoges@yahoo.com
Background: Surgical site infections are global healthcare problems. Although surgical site infections are preventable, they still cause significant morbidity, high death rates, and financial stress on national budgets and individual patients. Inappropriate uses of surgical antimicrobial prophylaxis are increasing and worsening patients' quality of life. This study determined the incidence and risk factors of surgical site infections.

Methods: Institution-based retrospective cross-sectional study was conducted using a structured data abstraction format on patients who were attending at the surgical ward of Borumeda hospital from April 1, 2017, to March 31, 2019. The data were collected during July 15-30, 2019. A systematic random sampling technique was employed to select 227 surgical cases. Multivariate logistic regression was computed using the statistical package for social sciences version 23.

Results: The incidence of surgical site infections was $46.7 \%$. Prophylaxis was administered to 188 (82.8\%) surgical cases. Prophylaxis was recommended for $151(66.5 \%)$. Out of these, only $143(94.7 \%)$ received prophylaxis. One hundred seventy-four $(78.4 \%)$ of the procedures had appropriate indication. The compliance of surgical antimicrobial prophylaxis use was $13.7 \%$. The predictors of surgical site infections were receiving prophylaxis more than $24 \mathrm{~h}$ after surgery $(\mathrm{AOR}=3.53,95 \% \mathrm{CI}: 1.22-10.17)$, clean-contaminated wounds $(\mathrm{AOR}=4.54,95 \% \mathrm{CI}$ : 1.33-15.53), surgical procedure of thyroidectomy ( $\mathrm{AOR}=5.2,95 \% \mathrm{CI}: 0.9-21.4)$, appendectomy $(\mathrm{AOR}=29,95 \% \mathrm{CI}: 6.2-141.7)$, cholecystectomy $(\mathrm{AOR}=21,95 \% \mathrm{CI}: 3.5-126.7)$, hernia $(\mathrm{AOR}=8.8,95 \% \mathrm{CI}: 1.2-62.2)$, skin and deep tissue $(\mathrm{AOR}=125,95 \% \mathrm{CI}: 7.8-196.7)$, and orthopedic (AOR=57, 95\% CI: 1.6-209.5).

Conclusion: There was high inconsistency between surgical antimicrobial prophylaxis practice and international surgical site infections prevention guideline. Wrong selection of antimicrobial agents was the most noncompliant to the guidelines. The incidence of surgical antimicrobial prophylaxis was high and requires due attention. The duration of postoperative prophylaxis should be kept to less than $24 \mathrm{~h}$.

Keywords: surgical site infection, antimicrobial prophylaxis, Borumeda hospital

\section{Introduction}

Surgical antimicrobial prophylaxis (SAP) is the use of antibiotics before, during, or after a surgical procedure to prevent infectious complications. ${ }^{1}$ It is the use of antibiotics for prevention and does not include preoperative decolonization or 
treatment of established infections. Surgical site infections are infections related to an operative procedure that occurs at or near the surgical incision within 30 days of the procedure or within 90 days if prosthetic material is implanted. $^{2}$

Surgical site infections are a global healthcare problem increasing patient morbidity, mortality, and healthcare cost. $^{3,4}$ They are the most frequent type of healthcareassociated infections in low- and middle-income countries, affecting up to one-third of operated patients, and the second most frequent type of healthcare-associated infections in high-income countries. ${ }^{4,5}$ Although SSIs are preventable healthcare-associated infections, they remain a substantial cause of morbidity, prolonged hospitalization, high death rates, and financial stress on national budgets and individual patients and have significant impact on patients' quality of life. . $^{2,6}$

The most important risk factors for SSIs were the general health of the patients (obesity, malnutrition, diagnosis of diabetes, multiple preoperative comorbid conditions), the level of bacterial contamination associated with the specific operative procedure, massive transfusion, recent surgery, corticosteroid use, extremes of age, gender, American Society of Anesthesiologists score (3, 4, or 5), type of surgical technique, and wound classification. ${ }^{7-11}$

Surgical antimicrobial prophylaxis is effective in preventing SSIs for all types of surgery ${ }^{12}$ and indicated for all clean-contaminated, contaminated, and dirty wounds. ${ }^{13}$ Since the risk of SSI in clean wounds which do not involve insertion of implants is low, the use of SAP is controversial. $^{14,15}$ Critical aspects of SAP administration are: giving the appropriate antimicrobial agent in adequate dose, proper preoperative prophylaxis timing, and maintaining drug level throughout the operation. ${ }^{16}$

Different guidelines for the prevention of SSI have been developed by the American Society of Health-System Pharmacist (ASHP), World Health Organization, ${ }^{17}$ Centers for disease control (CDC) and Healthcare Infection Control Practices Advisory Committee, and the National Institute for Clinical Excellence. ${ }^{18-22}$ Despite the availability of these guidelines, different studies have demonstrated inappropriate timing, selection, and excess duration of administration of antimicrobial prophylaxis. $^{23}$

Approximately $30-50 \%$ of the antimicrobials in hospitals were used for surgical prophylaxis. However, between $30-90 \%$ of this prophylaxis was inappropriate. ${ }^{24}$ Such inappropriate use of antimicrobial agents strongly calls for the evaluation of SAP. Periodic surveillance and feedback to surgeons on the rate of SSIs and their risk factors can reduce up to $50 \%$ of SSIs. ${ }^{17,25}$ The objectives of this study were to evaluate antimicrobial prophylaxis, to determine the incidence of SSI, and to identify associated risk factors at the surgical ward of BMH. Thus, this study provides vital baseline information on incidence rate and risk factors associated with SSI in the surgical ward of $\mathrm{BMH}$.

\section{Methods}

\section{Study Setting}

The study was conducted at BMH, North East Ethiopia. It is located 411 kilometers North of Addis Ababa. The hospital serves 2-4 million residents. It has different departments; medical ward, outpatient, pediatric, gynecology, surgical ward, ophthalmic, dermatology, psychiatry, and multidrug resistance Tuberculosis isolated room.

\section{Study Design and Period}

Institution-based retrospective cross-sectional study was conducted from July 15 to 30, 2019.

\section{Study Population}

Patients who underwent surgical procedures at the surgical ward of BMH from April 1, 2017, to March 31, 2019, and which fulfilled the inclusion criteria were the study population.

\section{Inclusion and Exclusion Criteria}

Patients with clean, clean contaminated, and contaminated types of wounds were included in this study.

Patients with dirty/infected wounds and patients with previous existing infection and antimicrobial treatment were excluded. This was to differentiate between prophylactic and treatment courses.

Patients whose records contained incomplete information and illegible handwriting were also excluded.

\section{Sample Size Determination}

Sample size was determined using a single population proportion formula. ${ }^{26}$ In a study conducted in a tertiary care teaching hospital in Addis Ababa, the proportion of SAP utilization was found to be $41 \%{ }^{27}$ Using tolerable sampling error at $5 \%$ and $95 \%$ confidence level, the required sample size was determined as follows: 


$$
n=\frac{(Z \alpha / 2)^{2} * p *(1-p)}{(D)^{2}}
$$

Where $\mathrm{n}=$ the required sample size, $Z=$ Confidence level at $95 \%$ (standard value $=1.960$ ), $P=$ proportion of SAP utilization $=41 \%$, and $D=$ Margin of error at $5 \%(0.05)$.

$$
n=\frac{(1.96)^{2} \times 0.41(1-0.41)}{(0.05)^{2}}=372
$$

Since the sample was withdrawn from a finite population (the source population was less than 10,000), the sample size was adjusted using Cochran's formula for calculating sample size when population size is finite. ${ }^{28}$

$$
n_{f}=\frac{n}{1+(n / N)^{2}}
$$

where $n_{f}=$ final sample size and $\mathrm{N}=$ total number of patient charts during the 2 years.

$$
n_{f}=\frac{372}{1+(372 / 582)}=227
$$

\section{Sampling Techniques}

Systematic random sampling technique was used to select patient charts. Five hundred eighty-two patient charts from April 1, 2017, to 31 March, 2019, were retrieved from the hospital's data clerks' office. The 582 patient charts were arranged chronologically and were used as the sampling frame. The sampling interval was determined by dividing the number of patient charts by the required sample size $(582 / 227=3)$. The first patient chart was selected by simple random sampling technique. Then, every third patient chart was selected until the required sample size was reached. If a patient chart did not contain complete information nor has illegible handwriting, the immediate next patient chart was selected.

\section{Study Variables Dependent Variable Incidence of SSI.}

\section{Independent Variables}

Age and gender of patients, type of surgery, comorbidity, wound classification, preoperative prophylaxis, postoperative prophylaxis, duration of postoperative prophylaxis.

\section{Definitions}

SSIs are infections related to an operative procedure that occurs at or near the surgical incision within 30 days of the procedure or within 90 days if prosthetic material is implanted. They include organ/space and deep, and superficial infections. $^{2}$

Appropriate antimicrobial prophylaxis indication: indication of a prophylactic antimicrobial agent that is consistent with AHSP SSI prevention guideline recommendations. ${ }^{19,20}$

Appropriate prophylactic antimicrobial regimens: following AHSP SSI prevention guideline recommendations in the components: right dose, right route, right time of administration of preoperative prophylaxis, right time of administration of intraoperative (re-dose) prophylaxis, right duration of postoperative prophylaxis. ${ }^{19,20}$

Clean wound: elective, not emergency, nontraumatic, and primarily closed; no acute inflammation; no break in technique; respiratory, gastrointestinal, biliary, and genitourinary tracts not entered.

Clean contaminated wound: urgent or emergency case that is otherwise clean; elective opening of respiratory, gastrointestinal, biliary, or genitourinary tract with minimal spillage (eg, appendectomy) not encountering infected urine or bile; minor technique break.

Contaminated wound: non-purulent inflammation; gross spillage from gastrointestinal tract; entry into biliary or genitourinary tract in the presence of infected bile or urine; major break in technique; penetrating trauma $<4$ hours old; chronic open wounds to be grafted or covered. ${ }^{29}$

\section{Surgical Antimicrobial Prophylaxis Use Evaluation Protocol}

The compliance of SAP practice guideline recommendations was evaluated by comparing the following parameters against ASHP recommendations: ${ }^{20}$ indication, choice of antimicrobial agent, dose, route of administration, time of administration of the first preoperative dose, and duration of postoperative prophylaxis. Based on the recommendations of ASHP, the following criteria were set for evaluation of SAP usage:

1. Indication was categorized as

- Appropriate - if prophylaxis was indicated and administered or if prophylaxis was not indicated and not administered.

- Inappropriate - if prophylaxis was indicated but not administered or if prophylaxis was not indicated but administered.

2. The choice of antimicrobial agent was categorized as follows based on the spectrum of coverage and 
bacteria most likely to be encountered at the specific surgical site:

- Adequate - covered anticipated bacteria.

- Narrow - did not cover the range of bacteria anticipated, and

- Broad or unnecessary combination - covered bacteria more than anticipated at the surgical site.

3. Time of administration of the first preoperative dose:

- Appropriate - if given within 30-60 min before incision.

- Too early - if given more than $1 \mathrm{~h}$ before incision was made.

- Late - if given between 0 and 29 min before incision.

4. Route:

- Appropriate - if given IV.

- Inappropriate - if given with other than IV route.

5. Duration of postoperative prophylaxis:

- Appropriate - if given within $24 \mathrm{~h}$ after the end of surgery.

- Inappropriate - if extended for more than 24 $\mathrm{h}$ after surgery.

For surgical cases in which the indication of prophylaxis was not appropriate, the other parameters were not evaluated. If there were surgical cases in which more than one antimicrobial agent was administered for a single operation, each agent was evaluated separately. In such cases, if the use of one of the agents was found to deviate from the guideline recommendations, the whole prophylactic course was considered as inappropriate as this can lead to antimicrobial resistance. Overall compliance to guideline recommendations was determined using the cases in which prophylaxis was indicated and administered with appropriate choice of antimicrobial agent, dose, route of administration, time of administration of the first preoperative dose and duration of postoperative prophylaxis and the cases in which prophylaxis was not indicated and not administered.

Finally, SAP was considered compliant if it satisfied the above-mentioned criteria for all drugs prescribed. If data for a given parameter were lacking, this was classified as missing data.

\section{Data Collection and Management}

The data were collected by two trained nurses who had no working relation to the hospital after recruiting and training with the supervision of the principal investigators using a data abstraction format which was developed after reviewing relevant literatures such as SSI prevention guidelines of AHSP, WHO, CDC and Healthcare Infection Control Practices Advisory Committee and different studies. ${ }^{19-21}$ The data collection instrument consisted of four sections: section one contained patient characteristics that might account for differences in occurrence of SSI. Section two contained disease information including type of surgery, type of procedure, and wound classification. Section three was targeted on SSI including: occurrence and time of onset. Section four focused on antimicrobial prophylaxis utilization review including: indication, name of antimicrobials prescribed as prophylactic agent, time of administration, dose, route of administration, and duration of postoperative prophylaxis.

To assure the quality of data, the data collection instrument was properly designed and pretested on 20 patient charts in Dessie Referral Hospital. All completed formats were examined for completeness and consistency during data management, storage, and analysis.

\section{Data Entry and Processing}

The completed formats were coded individually and entered in a computer using Epi-info version 3.5.1 and then exported to SPSS version 23.0 for analysis. Univariate analyses were used to describe the categorical variables (frequency and percentage distributions of different characteristics). Means and standard deviations were used to describe continuous variables. Multivariate logistic regression was performed to assess the presence and degree of association between the occurrence of SSI and the potential risk factors. To identify candidate variables for multiple logistic regression, bivariate logistic regression was performed. Those variables with a p-value of less than 0.2 were fitted to multivariate logistic regression. Model fitness was tested using the Hosmer and Lemeshow's test and it was insignificant. Variables with a p-value of below 0.05 in the multivariate logistic model were considered statistically significant factors. Adjusted odds ratios with the respective $95 \%$ confidence intervals were reported and interpreted.

\section{Results}

\section{Demographic and Surgical Characteristics of Patients}

A total of 227 surgical case records of patients that met the inclusion criteria were included in this study. The majority $146(64.3 \%)$ of the patients were males. The mean age of 
the study population was $40.58 \pm 19.6$ years $($ mean \pm SD) . The minimum and maximum age ranges were 2 months and 84 years. Nearly half $109(48 \%)$ of the patients were in the age category of greater than 40 years. The majority $217(95.6 \%)$ of the patients did not have any comorbid condition. Elective surgical procedures were done to 162 $(71.4 \%)$ of the patients. Clean-contaminated procedures were done to $109(48 \%)$ of the patients, while contaminated procedures were done only to $36(15.9 \%)$ patients (Table 1).

\section{Indication and Administration of Antimicrobial Prophylaxis}

Surgical antimicrobial prophylaxis was recommended for $151(66.5 \%)$ patients. Out of these, only $143(94.7 \%)$

Table I Demographic and Surgical Data of Patients Who Underwent Surgical Procedures at BMH from April 2017 to March $2019(\mathrm{~N}=227)$

\begin{tabular}{|c|c|c|c|}
\hline Variables & & Frequency & Percentage \\
\hline \multirow[t]{2}{*}{ Gender } & Male & 146 & 64.3 \\
\hline & Female & 81 & 35.7 \\
\hline \multirow[t]{4}{*}{ Age group } & $\leq 12$ & 44 & 19.4 \\
\hline & $13-30$ & 43 & 18.9 \\
\hline & $31-40$ & 31 & 13.7 \\
\hline & $>40$ & 109 & 48 \\
\hline \multirow[t]{2}{*}{ Type of surgery } & Elective & 162 & 71.4 \\
\hline & Emergency & 65 & 28.6 \\
\hline \multirow{8}{*}{$\begin{array}{l}\text { Type of } \\
\text { procedure }\end{array}$} & Thyroidectomy & 32 & 14.1 \\
\hline & Appendectomy & 48 & 21.1 \\
\hline & Cholecystectomy & 16 & 7.0 \\
\hline & Hernia & 22 & 9.7 \\
\hline & $\mathrm{BPH}$ & 25 & 11.0 \\
\hline & Orthopedic & II & 4.8 \\
\hline & Skin and deep & 23 & 10.1 \\
\hline & Miscellaneous & 50 & 22.0 \\
\hline \multirow{3}{*}{$\begin{array}{l}\text { Wound } \\
\text { classification }\end{array}$} & Clean & 82 & 36.1 \\
\hline & $\begin{array}{l}\text { Clean- } \\
\text { contaminated }\end{array}$ & 109 & \\
\hline & Contaminated & 36 & 15.9 \\
\hline \multirow{2}{*}{$\begin{array}{l}\text { Comorbid } \\
\text { condition }\end{array}$} & Yes & 10 & 4.4 \\
\hline & No & 217 & 95.6 \\
\hline \multirow{4}{*}{$\begin{array}{l}\text { Type of } \\
\text { comorbidity }\end{array}$} & Hypertension & 3 & 30 \\
\hline & Diabetes mellitus & 3 & 30 \\
\hline & Malnutrition & 1 & 10 \\
\hline & Other* & 3 & 30 \\
\hline
\end{tabular}

Note: *Use of corticosteroids, HIV, tuberculosis, psychosis. patients received prophylaxis. Out of those patients who did not need prophylaxis, 45 (59.2\%) had unnecessarily received antimicrobial prophylaxis. Among the patients who had no indication for prophylaxis, 31 (40.8) patients did not receive prophylaxis (Table 2). Out of 82 patients who had a clean wound, $51(62.2 \%)$ patients received prophylaxis, and out of 109 patients who had clean-contaminated wound, 105 (96.3\%) patients received prophylaxis, while all the patients who had contaminated wound received antimicrobial prophylaxis.

\section{Selection of Antimicrobials Used as Prophylactic Agent}

Surgical antimicrobial prophylaxis was administered to $188(82.8 \%)$ of the patients. Ceftriaxone was the most frequently prescribed antimicrobial in both preoperative $79(68.7 \%)$ and postoperative $104(67.5 \%)$ prophylaxes. Cephalexin with metronidazole was the least frequently used regimen (Table 3).

\section{Evaluation of Antimicrobial Prophylaxis Use Against Guideline Recommendations} Out of the patients for whom SAP was recommended, only $143(94.7 \%)$ received prophylaxis and out of those who had no indication, 31 (40.8) did not receive prophylaxis. Therefore, overall SAP indication was appropriate for 174 (78.4\%) patients. Out of the patients for whom SAP was indicated and administered, $110(76.9 \%)$ received accurate doses. Out of the patients for whom prophylaxis was indicated and administered, nearly all $(95.8 \%)$ of the patients were given broad-spectrum antibiotics or unnecessary combinations, while $6(4.2 \%)$ of them received antimicrobial agents which are not adequate to cover the

Table 2 Indication of SAP at BMH from April 2017 to March 2019

\begin{tabular}{|l|l|l|}
\hline Variables & Frequency & Percentage \\
\hline $\begin{array}{l}\text { Antimicrobial prophylaxis indicated } \\
\text { and administered }(n=151)\end{array}$ & 143 & 94.7 \\
\hline $\begin{array}{l}\text { Antimicrobial prophylaxis not } \\
\text { indicated and not administered }(n= \\
76)\end{array}$ & 31 & 40.8 \\
\hline $\begin{array}{l}\text { Antimicrobial prophylaxis indicated, } \\
\text { but not administered }(n=151)\end{array}$ & 8 & 5.3 \\
\hline $\begin{array}{l}\text { Antimicrobial prophylaxis not } \\
\text { indicated, but administered }(n=76)\end{array}$ & 45 & 59.2 \\
\hline
\end{tabular}


Table 3 Antimicrobials Prescribed as Preoperative $(n=1 \mid 4)$ and Postoperative $(n=154)$ Prophylactic Agents at $\mathrm{BMH}$ from April 2017 to March 2019

\begin{tabular}{|l|l|l|}
\hline Antimicrobial Agent & $\begin{array}{l}\text { Preoperative n } \\
\text { (\%) }\end{array}$ & $\begin{array}{l}\text { Postoperative n } \\
\text { (\%) }\end{array}$ \\
\hline Ceftriaxone & $79(68.69)$ & $104(67.5)$ \\
\hline $\begin{array}{l}\text { Ceftriaxone + } \\
\text { Metronidazole }\end{array}$ & $18(15.7)$ & $4 I(26.6)$ \\
\hline Ciprofloxacin & $8(7.0)$ & - \\
\hline $\begin{array}{l}\text { Cephalexin + } \\
\text { Metronidazole }\end{array}$ & $4(3.4)$ & $4(2.5)$ \\
\hline Cloxacillin & $5(4.3)$ & $5(3.2)$ \\
\hline
\end{tabular}

bacteria most likely to be encountered at the specific surgical site. None of the select antibiotics were appropriate for the surgical procedures. The time of administration of the first preoperative dose was missing for all cases. Of the patients who received postoperative prophylaxis, 76 (66.7\%) received their prophylaxis within $24 \mathrm{~h}$ after surgery. Selection of antimicrobial agents was the most common deviant from guideline recommendations (100\%) followed by duration of postoperative prophylaxis (33.3\%) (Table 4).

Table 4 Evaluation of SAP Use Among Patients Who Underwent Surgical Procedures at BMH from April 2017 to March 2019

\begin{tabular}{|c|c|c|}
\hline Variables & Frequency & Percentage \\
\hline \multicolumn{3}{|l|}{ Indication } \\
\hline Appropriate & 178 & 78.4 \\
\hline Inappropriate & 49 & 21.6 \\
\hline \multicolumn{3}{|l|}{ Choice $(n=143)$} \\
\hline Adequate & 0 & 0 \\
\hline Narrow & 6 & 4.2 \\
\hline Broad/unnecessary combination & 137 & 95.8 \\
\hline \multicolumn{3}{|l|}{ Dose $(n=143)$} \\
\hline Accurate & 110 & 76.9 \\
\hline Sub-dose & 5 & 3.5 \\
\hline Over-dose & 28 & 19.6 \\
\hline \multicolumn{3}{|l|}{ Route $(n=143)$} \\
\hline Appropriate & 143 & 100 \\
\hline Inappropriate & 0 & 0 \\
\hline \multicolumn{3}{|l|}{$\begin{array}{l}\text { Duration of postoperative prophylaxis } \\
(\mathrm{n}=1 \mid 4)\end{array}$} \\
\hline$<24$ hours & 76 & 66.7 \\
\hline$\geq 24$ hours & 38 & 33.3 \\
\hline
\end{tabular}

\section{Compliance of Surgical Antimicrobial}

Prophylaxis with Guideline

\section{Recommendations}

Of the 143 (63\%) patients who had indications for prophylaxis and received prophylaxis, compliance to all the stated criteria was $0 \%$. On the other hand, 31 (13.7\%) patients had no indication and did not receive prophylaxis. Therefore, the overall compliance to ASHP guideline recommendations was $13.7 \%$ (Figure 1).

\section{Incidence of Surgical Site Infection}

Out of the 227 patients included in this study, 106 (46.7\%) developed SSI. The majority, $100(94.33 \%)$ of the SSIs occurred within 30 days after the surgical procedure was done.

\section{Factors Associated with Increased Risk of Surgical Site Infection}

Multivariate logistic regression of potential determinants of increased risk of SSI revealed that gender, age, comorbidity, and type of surgery did not show statistically significant $(\mathrm{P}>0.05)$ association with risk of SSI. On the other hand, type of procedure, wound classification, and duration of postoperative prophylaxis were significantly $(\mathrm{P}<0.05)$ associated with occurrence of SSI.

Patients who underwent thyroidectomy procedure were 5.2 times more likely to develop SSI than those who underwent $\mathrm{BPH}$ procedure $(\mathrm{AOR}=5.2,95 \% \mathrm{CI}: 0.9-21.4, \mathrm{p}=$ 0.00 ) and Patients who underwent appendectomy procedure were 29 times more likely to develop SSI than those who underwent $\mathrm{BPH}$ procedure $(\mathrm{AOR}=29,95 \% \mathrm{CI}: 6.2-141.7$, $\mathrm{p}=0.00)$. Those patients who had clean-contaminated wounds were 4.5 times more likely to develop SSI than those who had contaminated wounds $(\mathrm{AOR}=4.54,95 \% \mathrm{CI}$ : $1.33-15.53)$. Patients who received postoperative prophylaxis for greater than $24 \mathrm{~h}$ after surgery had 3.5 times higher risk of developing SSI than those who received postoperative prophylaxis with less than 24 -h period after surgery $(\mathrm{AOR}=3.5,95 \%$ CI: 1.22-10.17, $\mathrm{p}=0.02)($ Table 5).

\section{Discussion}

This study was intended to evaluate antimicrobial prophylaxis, to determine the incidence of SSI, and to identify associated risk factors at the surgical ward of BMH. The majority $188(82.8 \%)$ of the patients received antimicrobial prophylaxis. This was higher than studies done in Ayder referral hospital, North Ethiopia $(62.2 \%){ }^{30}$ Tanzania 


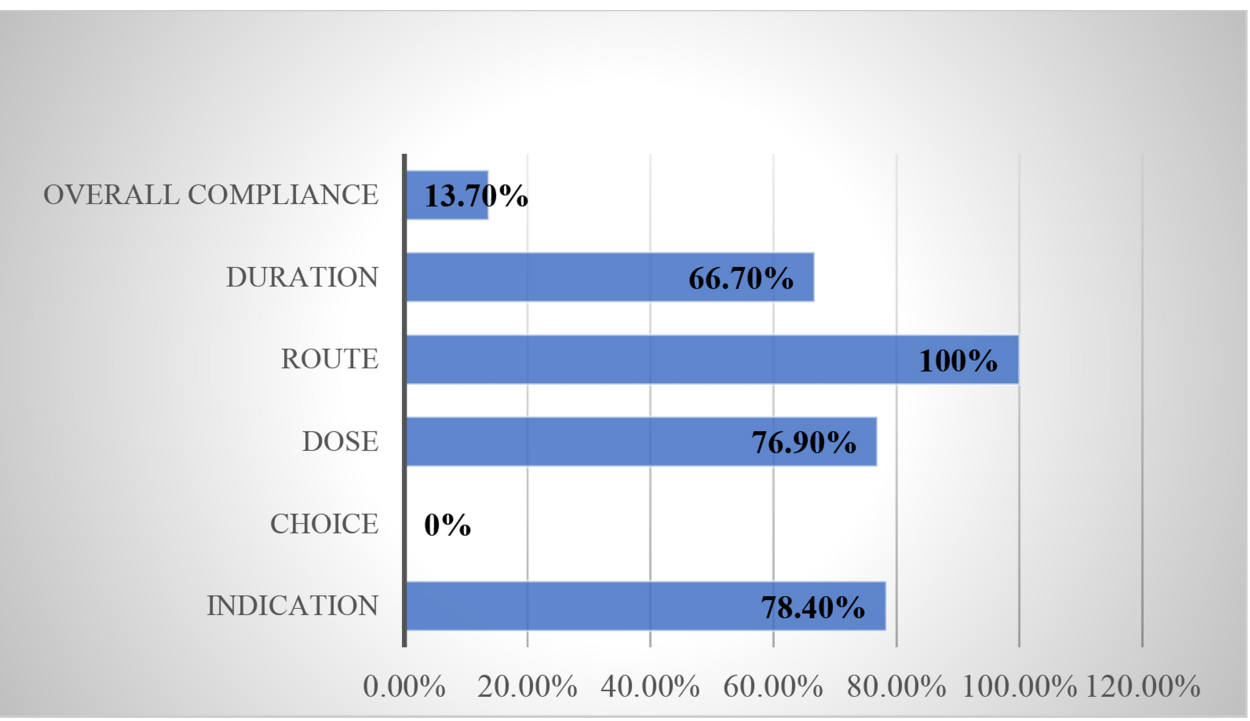

Figure I Compliance of SAP use among patients who underwent surgical procedures at BMH from April 2017 to March 2019 with AHSP SSI prevention guideline.

$(26.0 \%),{ }^{31}$ and Iran $(75 \%),{ }^{32}$ but lower than a study done in Sudan $(99.4 \%) .{ }^{33}$ Comparable findings were documented in studies conducted in St. Paul hospital, millennium medical college, Addis Ababa, Ethiopia (82.6\%), ${ }^{34}$ and Italy $(81.4 \%){ }^{35}$

Different guidelines recommend prophylaxis for all clean-contaminated, contaminated, and dirty procedures. ${ }^{13}$ Since the risk of SSI in most clean operations is low, SAP is not recommended in such procedures. ${ }^{14,15}$ However, in clean procedures such as breast cancer operations, SAP is recommended. ${ }^{36}$ In the present study, more than half (62.2\%) of the patients who had clean wound received prophylaxis, while nearly all $(96.3 \%)$ of the patients who had clean-contaminated wound and all the patients who had contaminated wound received antimicrobial prophylaxis. Therefore, nonselective use of antimicrobial prophylaxis

Table 5 Association of Selected Variables with SSI Among Patients Who Underwent Surgery at Surgical Wards of BMH from April 2017 to March 2019

\begin{tabular}{|c|c|c|c|c|}
\hline \multirow[t]{2}{*}{ Variables } & \multicolumn{2}{|c|}{ SSI Occurred } & \multirow[t]{2}{*}{ AOR $(95 \% \mathrm{CI})$} & \multirow[t]{2}{*}{$\mathbf{P}$} \\
\hline & Yes $n(\%)$ & No $n(\%)$ & & \\
\hline \multicolumn{5}{|l|}{ Type of procedure } \\
\hline Thyroidectomy & $7(21.9)$ & $25(78.1)$ & $5.2(0.9-21.4)$ & 0.00 \\
\hline Appendectomy & $38(79.2)$ & $10(20.8)$ & $29(6.2-141.7)$ & 0.00 \\
\hline Cholecystectomy & $\mathrm{II}(68.8)$ & $5(3 \mid .2)$ & $21(3.5-126.7)$ & 0.00 \\
\hline Hernia & $5(22.7)$ & I7(77.3) & $8.8(1.2-62.2)$ & 0.03 \\
\hline Skin and deep tissue & $20(87.0)$ & $3(13.0)$ & $125(7.8-196.7)$ & 0.00 \\
\hline Orthopedic & $7(63.6)$ & $4(36.4)$ & $57(1.6-209.5)$ & 0.03 \\
\hline Miscellaneous & $14(28.0)$ & $36(72.0)$ & $3(0.6-15.1)$ & 0.18 \\
\hline $\mathrm{BPH}$ & $4(16.0)$ & $2 \mathrm{I}(84.0)$ & 1.00 & \\
\hline \multicolumn{5}{|l|}{ Wound class } \\
\hline Clean & $25(30.5)$ & $57(69.5)$ & $2.5(0.5 I-12.83)$ & 0.25 \\
\hline Clean-contaminated & $63(57.8)$ & $46(42.2)$ & $4.5(1.33-15.53)$ & 0.01 \\
\hline Contaminated & $18(50.0)$ & $18(50.0)$ & 1.00 & \\
\hline \multicolumn{5}{|c|}{ Duration of postoperative prophylaxis } \\
\hline$\geq 24$ hour & $38(84.4)$ & $7(15.6)$ & $3.5(1.22-10.17)$ & 0.02 \\
\hline$<24$ hours & $68(62.4)$ & $4 I(37.6)$ & 1.00 & \\
\hline
\end{tabular}

Notes: $\mathrm{Cl}$ - confidence interval, I.00 - reference group. 
was observed in more than half of the patients who had clean wounds.

Surgical antimicrobial prophylaxis indication was appropriate for 174 (76.7\%) patients. Comparable finding was documented in studies conducted in Nicaragua (77\%), ${ }^{37}$ Mekelle, Ethiopia (80.6\%), ${ }^{30}$ and a lower finding was documented in a study conducted in Italy $(19.1 \%) .{ }^{35}$

Cefazolin is the first choice of antimicrobial agent for surgical prophylaxis according to both the ASHP and local treatment guidelines. ${ }^{20,38}$ In contrast to this, in the present study, out of the patients for whom prophylaxis was indicated and administered, nearly all (95.8\%) patients received ceftriaxone, third-generation broad-spectrum cephalosporin, as single or combination regimens. Thirdgeneration cephalosporins are not recommended for surgical prophylaxis for different reasons: they are active against bacteria rarely encountered in elective surgery, their wide-spread use is associated with the emergence of bacterial resistance, they are less active against staphylococci which are the most common organisms responsible for SSIs, and they are generally expensive. ${ }^{39}$ Therefore, broad-spectrum antimicrobials should be used to treat postoperative infections but not for antimicrobial prophylaxis. ${ }^{40}$ Third-generation broad-spectrum antimicrobials also suppress the normal flora of patients and make it easier for susceptible patients to be infected by drug-resistant organisms in the hospital, ${ }^{41}$ and this might increase the incidence of SSI in hospitals.

The high utilization rate of third-generation broadspectrum cephalosporin in the present study might be due to unavailability of first and second-generation cephalosporins, affordability and availability of ceftriaxone, belief of broad/multiple antibiotics are more effective in preventing SSIs, low adherence of healthcare professionals to hospital protocols. Similar higher utilization rates of ceftriaxone for surgical prophylaxis were documented by other studies conducted in different parts of Ethiopia. ${ }^{30,42,43}$

Of the patients for whom prophylaxis was indicated and administered, $6(4 \%)$ received antimicrobial agents which are not adequate to cover the bacteria most likely to be encountered at the specific surgical site, and hence none of the select antibiotics were appropriate for the surgical procedures. Cefazolin, which is the first choice of antimicrobial agent for surgical prophylaxis according to both the ASHP and local treatment guidelines, was administered to none of the patients in the present study. Similar finding was documented by Halawi et al. ${ }^{43}$
Preoperative antimicrobial prophylaxis should be started within 30-60 min prior to the start of the operation for an adequate intra-tissue concentration of the antimicrobial at the surgical site. ${ }^{20,44}$ However, in the present study preoperative prophylaxis administration time was not recorded in all patients who received preoperative antimicrobial prophylaxis. This might be due to work overload, absence of time recording sheet, lack of awareness on recording antimicrobial administration time, or lack of awareness by staff about the optimal timing of dosing and its role in infection prevention.

There was no re-doe of prophylaxis in all the surgical procedures. This might be due to the fact that ceftriaxone was the most frequently used antibiotic and it usually does not require re-dosing as it has a long half-life. ${ }^{20}$ In addition to ASHP guideline, many other guidelines recommend discontinuing SAP within $24 \mathrm{~h}$ after surgery. ${ }^{15,45,46}$ However, in the present study, of the patients who were indicated and administered postoperative prophylaxis, onethird (33.3\%) continued for over $24 \mathrm{~h}$ after surgery. This was lower than a study done in acute-care US hospitals and in a tertiary care center in Oman which documented extended postoperative prophylaxis for $59.3 \%$ and $69 \%$ of patients, respectively. ${ }^{47,48}$ This difference might be due to differences in study time. Since the later were conducted so earlier than the previous, surgeons might have better awareness about the impact of prolonged postoperative prophylaxis.

Out of the 143 patients for whom SAP was indicated and administered, $110(76.9 \%)$ patients received accurate doses. This was lower than studies conducted in Mekelle, North Ethiopia (89.6\%), ${ }^{30}$ but higher than studies conducted in Khartoum teaching hospital $(65.5 \%)^{33}$ and Sudanese teaching hospital $(29 \%) .{ }^{49}$ Of the dose deviations, overdosage takes the lion share and the majority of the patients who were overdosed were children under 12 years old. For most of the children, SAP doses were not based on their body weight.

The overall compliance of SAP use to ASHP SSI prevention guideline was $13.7 \%$. This finding was lower than studies done in Mekelle university teaching hospital $(25 \%),{ }^{30}$ Germany $(70.7 \%),{ }^{50}$ United States $(24.6 \%),{ }^{51}$ and Netherland (28\%), ${ }^{52}$ but higher than studies conducted in Khartoum teaching hospital $(6.7 \%),{ }^{33}$ Sudanese teaching hospital $(2.7 \%),{ }^{49}$ and Iran $(0.6 \%) .{ }^{53}$ The highest rate of noncompliance in the present study was observed in the selection of antimicrobial agent, $100 \%$ deviation from 
AHSP guideline recommendations, followed by extended duration of postoperative prophylaxis $(33.3 \%)$ deviation.

The overall incidence of SSI in the present study was $46.7 \%$. This was lower than the finding by Ragvir et al $(66 \%)^{54}$ but higher compared to the studies conducted in Hawassa university referral hospital, South Ethiopia $(19.1 \%),{ }^{55}$ Wolaita sodo university teaching and referral hospital, South Ethiopia (13\%), ${ }^{56}$ Sudan (10.9\%), ${ }^{33}$ and Nigeria $(20.3 \%) .{ }^{57}$ This variation might be due to differences in the selection of antimicrobial agents, infection control practices such as operating room ventilation, the equipment used, sterilization methods, availability of antimicrobial prophylaxis, and differences in study design and time. The increased SSI incidence in this study might be attributed to the irrational use of antimicrobials for surgical prophylaxis such as excessive use of broad-spectrum antimicrobials and improper timing of prophylactic dose. Administration of broad-spectrum antimicrobials suppresses the normal flora of patients and makes it easier for susceptible patients to be infected by drug-resistant organisms in the hospital. ${ }^{41}$

The present study identified the type of procedure, wound classification, and duration of postoperative prophylaxis as risk factors for the occurrence of SSI. These were also identified by other studies to be independent predictors of SSI. ${ }^{11,54,58-60}$ Patients who received postoperative prophylaxis for greater than $24 \mathrm{~h}$ after surgery had 3.5 times higher risk of developing SSI than those whose postoperative prophylaxis discontinued within $24 \mathrm{~h}$ after surgery. This can be attributed to the fact that prolonged use of prophylactic antimicrobials is associated with the emergence of resistant bacterial strains and the excess use of antimicrobials can contribute to secondary infections, such as those caused by Clostridium difficile. ${ }^{61,62}$

Those patients who had clean-contaminated wounds were 4.5 times more likely to develop SSI than those who had contaminated wounds. Similar finding was documented in a study conducted in a tertiary care teaching hospital in Addis Ababa, Ethiopia. ${ }^{42}$ The low incidence of SSIs in contaminated wounds than clean-contaminated wounds in the present study might be due to close attention taken to contaminated wounds at the time of the procedure since surgeons knew that there is high degree of bacterial contamination in this wound class.

Patients who underwent thyroidectomy, appendectomy, cholecystectomy, hernia, skin and deep, and orthopedic procedures had higher risk of developing SSI than those patients who underwent BPH procedures. This might be due to greater due attention to thyroidectomy, appendectomy, cholecystectomy, hernia, skin and deep, and orthopedic procedures than $\mathrm{BPH}$ operations.

\section{Limitations}

The study design was retrospective and hence data on modifiable risk factors such as techniques in the operating room, including sterile field, aseptic technique, personal protective equipment, and surgical hand hygiene antiseptics used for patient preparation, type of anesthesia used, and variables related to health professionals were not available from patient charts and not assessed in the present study.

\section{Conclusions}

There was high inconsistency between SAP practice at $\mathrm{BMH}$ and guideline recommendations. Wrong selection of antimicrobial agents was the most noncompliant to the guidelines. The incidence of SSI was high and requires due attention. Type of procedure, wound classification, and duration of postoperative prophylaxis were found to be risk factors for the occurrence of SSI.

Adherence to narrow-spectrum antimicrobials and ensuring availability and affordability of the antibiotics should be promoted. The duration of postoperative prophylaxis should be kept to less than $24 \mathrm{~h}$. Patients with clean wound require close attention like the patients with contaminated wound to reduce the incidence of SSI. Studies aimed at isolation of common microorganism responsible for SSI are recommended.

\section{Abbreviations}

AOR, Adjusted odds ratio; ASA, American Society of Anesthesiologists; ASHP, American Society of HealthSystem Pharmacist; CDC, center for disease control; $\mathrm{BMH}$, Borumeda hospital; SAP, surgical antimicrobial prophylaxis; SSI, Surgical site infection; WHO, World health organization.

\section{Data Sharing Statement}

The datasets used and/or analyzed during the current study are available from the corresponding author on reasonable request.

\section{Ethics Approval and Informed Consent}

Ethical clearance was obtained from Wollo University, College of Medicine and Health Sciences Ethical review 
board (CMHS-355/013/11). Letter of cooperation was written to BMH. Permission was obtained from Hospital management before starting data collection. Informed consent was not sought from each patient as it used secondary data. BMH gave consent on behalf of the patients and this was approved by Wollo University, College of Medicine and Health Sciences Ethical review board. Confidentiality of the information collected was maintained by omitting patient name and other personal identifiers from data abstraction format. This study was conducted in accordance with the Declaration of Helsinki.

\section{Acknowledgments}

The authors would like to express their gratitude to Wollo university for supporting materials, BMH for allowing us to access patient charts. We are also grateful to data collectors and staffs of BMH for their cooperation.

\section{Author Contributions}

All authors made substantial contributions to conception and design, acquisition of data, or analysis and interpretation of data; took part in drafting the article or revising it critically for important intellectual content; agreed to submit to the current journal; gave final approval of the version to be published; and agree to be accountable for all aspects of the work.

\section{Funding}

There is no funding to report.

\section{Disclosure}

The authors report no conflicts of interest for this work.

\section{References}

1. Misra AK, Gupta R, Bedi JS, Narang M, Garg S, Mail I. Antibiotic prophylaxis for surgical site infection: need of time. Health. 2015;3 (3): $1-7$.

2. Centers for Disease Control and Prevention. Surgical site infection (SSI) event. Procedure-associated module. 2017.

3. Allegranzi B, Nejad SB, Combescure C, et al. Burden of endemic health-care-associated infection in developing countries: systematic review and meta-analysis. Lancet. 2011;377(9761):228-241. doi:10.1016/S0140-6736(10)61458-4

4. Badia J, Casey A, Petrosillo N, Hudson P, Mitchell S, Crosby C. Impact of surgical site infection on healthcare costs and patient outcomes: a systematic review in six European countries. J Hosp Infect. 2017;96(1):1-15. doi:10.1016/j.jhin.2017.03.004

5. Zarb P, Coignard B, Griskeviciene J, et al. The European Centre for Disease Prevention and Control (ECDC) pilot point prevalence survey of healthcare-associated infections and antimicrobial use. Eurosurveillance. 2012;17(46):1-16. doi:10.2807/ese.17.46.20316-en
6. Hagel S, Ludewig K, Frosinski J, et al. Effectiveness of a hospital-wide educational programme for infection control to reduce the rate of healthcare associated infections and related sepsis (ALERTS)-methods and interim results. EuropePMC. 2013;138(34-35):1717-1722.

7. Borens O, Yusuf E, Trampuz A. Surgical Site Infections (SSIs): risk factors and prevention strategies. Eur Instruct Lect. 2013;15-24.

8. Karlsson EA, Beck MA. The burden of obesity on infectious disease. Exp Biol Med. 2010;235(12):1412-1424. doi:10.1258/ebm.2010.010227

9. Daneman N, Lu H, Redelmeier D. Discharge after discharge: predicting surgical site infections after patients leave hospital. $J$ Hosp Infect. 2010;75(3):188-194. doi:10.1016/j.jhin.2010.01.029

10. Shilling AM, Raphael J. Diabetes, hyperglycemia, and infections. Best Pract Res Clin Anaesthesiol. 2008;22(3):519-535. doi:10.1016/j. bpa.2008.06.005

11. Darouiche R. Surgical site infections. Hosp Infect Control. 2016;9 (3):12-15.

12. Bowater RJ, Stirling SA, Lilford RJ. Is antibiotic prophylaxis in surgery a generally effective intervention?: testing a generic hypothesis over a set of meta-analyses. Ann Surg. 2009;249(4):551-556. doi:10.1097/SLA.0b013e318199f202

13. Allegranzi B, Bischoff $\mathrm{P}$, de Jonge $\mathrm{S}$, et al. New WHO recommendations on preoperative measures for surgical site infection prevention: an evidence-based global perspective. Lancet Infect Dis. 2016;16 (12):e276-e287. doi:10.1016/S1473-3099(16)30398-X

14. de Jonge SW, Boldingh QJ, Solomkin JS, et al. Effect of postoperative continuation of antibiotic prophylaxis on the incidence of surgical site infection: a systematic review and meta-analysis. Lancet Infect Dis. 2020;20(10):1182-1192. doi:10.1016/S1473-3099(20) 30084-0

15. Workgroup SIPGW, Bratzler D, Houck P. Antimicrobial prophylaxis for surgery: an advisory statement from the National Surgical Infection Prevention Project. Am J Surg. 2005;189(4):395-404. doi:10.1016/j.amjsurg.2005.01.015

16. Dellinger EP. Prophylactic antibiotics: administration and timing before operation are more important than administration after operation. Clin Infect Dis. 2007;44(7):928-930. doi:10.1086/512198

17. WHO. Patient Safety, WHO Guidelines for Safe Surgery: Safe Surgery Saves Lives. World Health Organization; 2009.

18. Manyele S, Anicetus H, Bilia M Globalization and its effects on medical waste management in Tanzania. Paper presented at: IET Annual Conference and General Meeting, Arusha, 4th-5th December 2003.

19. Organization WH. Global Guidelines for the Prevention of Surgical Site Infection. World Health Organization; 2016.

20. Bratzler DW, Dellinger EP, Olsen KM, et al. Clinical practice guidelines for antimicrobial prophylaxis in surgery. Surg Infect (Larchmt). 2013;14(1):73-156. doi:10.1089/sur.2013.9999

21. Berríos-Torres SI, Umscheid CA, Bratzler DW, et al. Centers for disease control and prevention guideline for the prevention of surgical site infection, 2017. JAMA Surg. 2017;152(8):784-791. doi:10.1001/jamasurg.2017.0904

22. Leaper D, Burman-Roy S, Palanca A, et al. Prevention and treatment of surgical site infection: summary of NICE guidance. BMJ. 2008;337:a1924. doi:10.1136/bmj.a1924

23. Gagliardi AR, Fenech D, Eskicioglu C, Nathens AB, McLeod R. Factors influencing antibiotic prophylaxis for surgical site infection prevention in general surgery: a review of the literature. Can J Surg. 2009;52(6):481-489.

24. Friedman C, Sturm LK, Chenoweth C. Electronic chart review as an aid to postdischarge surgical site surveillance: increased case finding. $\mathrm{Am}$ J Infect Control. 2001;29(5):329-332. doi:10.1067/mic.2001.114401

25. Friedman C, Sturm L, Chenoweth C. Electronic chart review as an aid to post discharge surgical site surveillance: increased index for the prediction of surgical site infections: a review. Braz J Infect Dis. 2007;134-141. 
26. Pourhoseingholi MA, Vahedi M, Rahimzadeh M. Sample size calculation in medical studies. Gastroenterol Hepatol. 2013;6(1):14.

27. Argaw NA, Shumbash KZ, Asfaw AA, Hawaze AS. Assessment of surgical antimicrobial prophylaxis in Orthopaedics and Traumatology Surgical Unit of a Tertiary Care Teaching Hospital in Addis Ababa. BMC Res Notes. 2017;10(1):1-8. doi:10.1186/s13104-017-2475-2

28. Cochran WG. Sampling Techniques. John Wiley \& Sons; 2007.

29. Mangram AJ, Horan TC, Pearson ML, Silver LC, Jarvis WR; Committee HICPA. Guideline for prevention of surgical site infection, 1999. Infect Control Hosp Epidemiol. 1999;20(4):247-280.

30. Mohamoud SA, Yesuf TA, Sisay EA. Utilization assessment of surgical antibiotic prophylaxis at Ayder Referral Hospital, Northern Ethiopia. J Appl Pharm. 2016;8(02):1-5. doi:10.4172/19204159.1000220

31. Mawalla B, Mshana SE, Chalya PL, Imirzalioglu C, Mahalu W. Predictors of surgical site infections among patients undergoing major surgery at Bugando Medical Centre in Northwestern Tanzania. BMC Surg. 2011;11(1):1-7.

32. Foroutan B, Foroutan R. Perioperative antibiotic prophylaxis in elective surgeries in Iran. Med J Islam Repub Iran. 2014;28:1-7.

33. Elbur AI, Yousif M, El-Sayed AS, Abdel-Rahman ME. Prophylactic antibiotics and wound infection. J Clin Diagn Res. 2013;7 (12):2747-2751.

34. Alamrew K, Tadesse TA, Abiye AA, Shibeshi W. Surgical antimicrobial prophylaxis and incidence of surgical site infections at Ethiopian Tertiary-Care Teaching Hospital. Infect Dis. 2019;12 (1): $1-7$.

35. Napolitano F, Izzo MT, Di Giuseppe G, Angelillo IF, Landoni G; Group CW. Evaluation of the appropriate perioperative antibiotic prophylaxis in Italy. PLoS One. 2013;8(11):e79532. doi:10.1371/journal.pone. 0079532

36. Kappeler R, Gillham M, Brown NM. Antibiotic prophylaxis for cardiac surgery. J Antimicrob Chemother. 2012;67(3):521-522. doi: $10.1093 / \mathrm{jac} / \mathrm{dkr} 536$

37. Van Disseldorp J, Slingenberg E, Matute A, Delgado E, Hak E, Hoepelman I. Application of guidelines on preoperative antibiotic prophylaxis in León, Nicaragua. Neth J Med. 2006;64(11):411-416.

38. Food M, Administration HC, Ethiopia CAo. Standard Treatment Guidelines for General Hospitals. 2014.

39. Martin C, Pourriat J. Quality of perioperative antibiotic administration by French anaesthetists. J Hosp Infect. 1998;40(1):47-53. doi:10.1016/S0195-6701(98)90024-X

40. Yamamoto S, Shigemura K, Kiyota H, Arakawa S. Antimicrobial prophylaxis in urological surgery. Urogenital Tract Infect. 2016;11 (3):77-85. doi:10.14777/uti.2016.11.3.77

41. Lee S, Kim H, Kang H, Kim J, Chung D. Rapid spread of methicillin-resistant Staphylococcus aureus in a new hospital in the broad-spectrum antibiotic era. $J$ Infect. 2007;55(4):358-362. doi:10.1016/j.jinf.2007.06.011

42. Alemkere G, Hawryluk GWJ. Antibiotic usage in surgical prophylaxis: a prospective observational study in the surgical ward of Nekemte referral hospital. PLoS One. 2018;13(9):1-17. doi:10.1371/journal.pone.0203523

43. Halawi E, Assefa T, Hussen S. Pattern of antibiotics use, incidence and predictors of surgical site infections in a Tertiary Care Teaching Hospital. BMC Res Notes. 2018;11(1):1-6. doi:10.1186/s13104-0183643-8

44. Koch CG, Li L, Hixson E, et al. Is it time to refine? An exploration and simulation of optimal antibiotic timing in general surgery. $J \mathrm{Am}$ Coll Surg. 2013;217(4):628-635.

45. Hawn MT, Richman JS, Vick CC, et al. Timing of surgical antibiotic prophylaxis and the risk of surgical site infection. JAMA Surg. 2013;148(7):649-657. doi:10.1001/jamasurg.2013.134
46. Takesue Y, Mikamo H, Arakawa S, et al. Guidelines for implementation of clinical studies on surgical antimicrobial prophylaxis (2007). $J$ Infect Chemother. 2008;14(2):172-177. doi:10.1007/s10156-008-0588-1

47. Bratzler DW, Houck PM, Richards C, et al. Use of antimicrobial prophylaxis for major surgery: baseline results from the National Surgical Infection Prevention Project. Arch Surg. 2005;140 (2):174-182. doi:10.1001/archsurg.140.2.174

48. El-Shoubary W, Elsheikh M, Al Maani A. Evaluation of surgical antimicrobial prophylaxis practices in a tertiary care center in Oman, 2015. Antimicrob Resist Infect Control. 2015;4(S1):P177. doi:10.1186/2047-2994-4-S1-P177

49. Elbur AI, Yousif MAER, ElSayed ASA, Abdel-Rahman ME. An audit of prophylactic surgical antibiotic use in a Sudanese Teaching Hospital. Int J Clin Pharm. 2013;35(1):149-153. doi:10.1007/ s11096-012-9719-y

50. Hohmann C, Eickhoff C, Radziwill R, Schulz M. Adherence to guidelines for antibiotic prophylaxis in surgery patients in German hospitals: a multicentre evaluation involving pharmacy interns. Infection. 2012;40(2):131-137.

51. Goede WJ, Lovely JK, Thompson RL, Cima RR. Assessment of prophylactic antibiotic use in patients with surgical site infections. Hosp Pharm. 2013;48(7):560-567. doi:10.1310/hpj4807-560

52. Van Kasteren M, Kullberg BJ, De Boer A, Mintjes-de Groot J, Gyssens I. Adherence to local hospital guidelines for surgical antimicrobial prophylaxis: a multicentre audit in Dutch hospitals. J Antimicrob Chemother. 2003;51(6):1389-1396. doi:10.1093/jac/ dkg264

53. Vessal G, Namazi S, Davarpanah M, Foroughinia F. Evaluation of prophylactic antibiotic administration at the surgical ward of a major referral hospital, Islamic Republic of Iran. East Mediterr Health J. 2011;17(8):663-668. doi:10.26719/2011.17.8.663

54. Singh R, Singla P, Chaudhary U. Surgical site infections: classification, risk factors, pathogenesis and preventive management. Int J Pharm Res Health Sci. 2014;2(3):203-214.

55. Laloto TL, Gemeda DH, Abdella SH. Incidence and predictors of surgical site infection in Ethiopia: prospective cohort. BMC Infect Dis. 2017;17(1):119. doi:10.1186/s12879-016-2167-x

56. Awoke N, Arba A, Girma A, Kamolz L-P. Magnitude of surgical site infection and its associated factors among patients who underwent a surgical procedure at Wolaita Sodo University Teaching and Referral Hospital, South Ethiopia. PLoS One. 2019;14(12):1-11. doi:10.1371/journal.pone. 0226140

57. Nwankwo E, Ibeh I, Enabulele O. Incidence and risk factors of surgical site infection in a tertiary health institution in Kano, Northwestern Nigeria. Int J Infect Control. 2012;8(4):8-13.

58. Ortega G, Rhee DS, Papandria DJ, et al. An evaluation of surgical site infections by wound classification system using the ACS-NSQIP. J Surg Res. 2012;174(1):33-38. doi:10.1016/j.jss.2011.05.056

59. Mezemir R, Seid A, Gishu T, Demas T, Gize A. Prevalence and root causes of surgical site infections at an academic trauma and burn center in Ethiopia: a cross-sectional study. Patient Saf Surg. 2020;14 (3): $1-7$.

60. De SC, Chiumello D, Nicolini R, et al. Prolongation of antibiotic prophylaxis after clean and clean-contaminated surgery and surgical site infection. Minerva Anestesiol. 2010;76(6):413-419.

61. Harbarth S, Samore MH, Lichtenberg D, Carmeli Y. Prolonged antibiotic prophylaxis after cardiovascular surgery and its effect on surgical site infections and antimicrobial resistance. Circulation. 2000;101(25):2916-2921. doi:10.1161/01.CIR.101.25.2916

62. Hecker MT, Aron DC, Patel NP, Lehmann MK, Donskey CJ. Unnecessary use of antimicrobials in hospitalized patients: current patterns of misuse with an emphasis on the antianaerobic spectrum of activity. Arch Intern Med. 2003;163(8):972-978. doi:10.1001/ archinte.163.8.972 


\section{Publish your work in this journal}

Drug, Healthcare and Patient Safety is an international, peer-reviewed open-access journal exploring patient safety issues in the healthcare continuum from diagnostic and screening interventions through to treatment, drug therapy and surgery. The journal is characterized by the rapid reporting of reviews, original research, clinical, epidemiological and post-marketing surveillance studies, risk management, health literacy and educational programs across all areas of healthcare delivery. The manuscript management system is completely online and includes a very quick and fair peer-review system. Visit http://www.dovepress.com/testimonials.php to read real quotes from published authors. 